\title{
Articulação entre os níveis de atenção dos serviços de saúde na Região Metropolitana de Curitiba: desafios para os gestores
}

\author{
Sandra Lúcia Vieira Ulinski Aguilera \\ Pontifícia Universidade Católica do Paraná (PUC-PR) \\ Beatriz Helena Sottile França \\ Pontifícia Universidade Católica do Paraná (PUC-PR) \\ Simone Tetú Moysés \\ Pontifícia Universidade Católica do Paraná (PUC-PR) \\ Samuel Jorge Moysés \\ Pontifícia Universidade Católica do Paraná (PUC-PR)
}

\begin{abstract}
A provisão adequada de serviços de atenção primária à saúde e o acesso aos serviços especializados, também usualmente referidos como de média/alta complexidade, apresentam-se como uma dificuldade em vários municípios brasileiros, tendo em vista as questões gerenciais envolvidas que incluem a força de trabalho, os custos e a densidade tecnológica exigida. Este estudo objetivou compreender a prática discursiva de gestores em relação à articulação entre os níveis de atenção primária e de média/alta complexidade dos serviços públicos de saúde na Região Metropolitana de Curitiba (RMC). Realizouse um estudo exploratório de abordagem qualitativa com 17 gestores de saúde da RMC. Os dados discursivos foram coletados por meio de entrevista semiestruturada, sendo processados pelo método de análise de discurso. A interpretação do material permitiu a classificação dos dados discursivos, que foram agrupados em categorias: atenção primária municipal, acesso na média complexidade, atendimento hospitalar, saúde bucal e articulação política. A análise demonstrou que os municípios se encontram em diferentes estágios de implantação e organização da atenção primária. A dificuldade no acesso aos serviços de média/alta complexidade promove interrupção na continuidade das linhas de cuidado, as quais visam à integralidade da atenção em saúde e implicam a adequada coordenação da atenção primária articulada à atenção especializada de segundo e/ou terceiro níveis de densidade tecnológica.
\end{abstract}

Palavras-chave: políticas públicas de saúde; acesso aos serviços de saúde; níveis de cuidado em saúde; iniquidades em saúde.

Artigo recebido em 29 out. 2012 e aceito em 16 abr. 2013. 
Coordinación entre niveles asistenciales de los servicios de salud em la Región Metropolitana de Curitiba: desafíos para el gerentes

La prestación adecuada de los servicios de atención primaria a la salud y acceso a los servicios especializados, también conocidos comúnmente como la media/alta complejidad, se presenta como una dificultad en varias ciudades brasileñas, em vista de los cuestiones de gestión, incluyendo fuerza de trabajo, los costos y la densidad tecnológica necesario. Este estudio tuvo como objetivo comprender la práctica discursiva del directivos en relación a los servicios de salud en la Región Metropolitana de Curitiba (RMC). Se realizó un estudio exploratorio de abordaje cualitativo, con diecisiete gerentes de salud de RMC. Los datos fueron obtenidos mediante entrevista semi-estructurada y se procesaron mediante el método de análisis del discurso. La interpretación del material permitió la clasificación de los datos del discurso, que se agruparon en categorías: atención primaria municipal, acceso a la atención especializada, hospitalizaciones, salud bucal y articulación política. El análisis muestra que los municipios están en diferentes etapas de la atención primaria. La dificultad en acceso a los servicios de media/alta complejidad favorece la interrupción en la continuidad de las líneas de atención que tienen como objetivo la atención atención integral en salud e implican en la adecuada coordinación de la atención primaria articulada a la atención especializada de segundo y/o tercer nivel de densidade de tecnología.

Palabras clave: accesibilidad a los servicios de salud; equidad en el acceso; políticas públicas de salud; desigualdades en salud.

Articulation between levels of healthcare services in the Curitiba Metropolitan Area: challenges for managers

The appropriate provision of primary healthcare services and access to specialized services, also commonly referred as medium/high complexity, presents as a difficulty in several municipalities, considering the managerial issues involved including the workforce, cost and technological density required. This study aimed to understand the discursive practice of managers regarding the articulation between primary and middle/ high complexity levels of public health services in the Metropolitan Region of Curitiba (RMC). An exploratory study was conducted with seventeen health administrators in the CMA. The data were obtained in semi-structured interviews, being processed by speech analysis method. The material interpretation allowed the discourse data classification, which were grouped into categories: access of municipal primary care, medium complexity access, hospital care, oral health and political articulation. The analysis has shown that the municipalities are in different stages regarding primary health care. The difficulty in accessing medium/high complexity services promotes disruption in care lines continuity, which aim at comprehensive care in health and imply the proper coordination of primary care articulated to specialized care of second and/or third level of technology density.

KEYwords: health services accessibility; acess equity; health services; health public policy; health inequities.

\section{Introdução}

O Ministério da Saúde definiu a atenção especializada de média/alta complexidade como um conjunto de serviços ambulatoriais e hospitalares, além de recursos de apoio diagnóstico e 
terapêutico, dotados de maior densidade tecnológica que os diferenciam da Atenção Primária à Saúde (APS) (Brasil, 2001). O acesso a estes serviços apresenta-se como um importante problema, tanto para populações de pequenos municípios de regiões distantes de grandes centros urbanos, como para aqueles que integram regiões metropolitanas, seja pelos custos e/ou pela força de trabalho especializada envolvida (Brasil, 2004; Franco e Magalhães Júnior, 2003).

É pertinente pontuar que uma parcela da demanda assistencial encaminhada à atenção de média/alta complexidade ocorre devido à baixa resolutividade na APS, situação infelizmente ainda comum em vários municípios brasileiros, independentemente de seu porte populacional. Isto gera uma pressão da demanda e longas filas de espera por estes serviços no Sistema Único de Saúde (SUS) (Pires et al., 2010; Conass, 2007; Sarmento, Tomita e Kos, 2005).

Autores têm destacado a complexidade do desafio representado pela integralidade e resolutividade das ações e serviços do SUS (Campos, 2007; Levcovitz, Lima e Machado, 2001; Souza, 2002). O modelo de descentralização adotado pela política de saúde brasileira, em direção à municipalização das ações e serviços (incluindo a gestão de recursos e instrumentos), sobrecarregou o papel deste ente federado. Esse novo modelo estaria assentado na separação entre financiamento e provisão dos serviços, ficando o financiamento a cargo das três esferas de governo e a provisão dos serviços sob a responsabilidade dos municípios. As relações intergovernamentais, em um modelo que impõe relações bi e tripartites, geram zonas de indefinições e conflitos, com impasses em relação às funções e à governabilidade das secretarias estaduais de saúde para coordenar o sistema de referência intermunicipal. O nível federal, por sua vez, ampliou seu poder indutor e regulador ao introduzir novos mecanismos de transferência vinculados às ações e aos programas assistenciais, além de instrumentos de regulação do processo de descentralização.

Quanto ao financiamento global do sistema e as respectivas partilhas entre os agentes públicos envolvidos, têm sido frequentes os embates ao longo das duas últimas décadas. Diversos aspectos que definem as responsabilidades e contrapartidas do financiamento são contestados, particularmente por secretários municipais. Há tensões também com a área econômica do governo federal e com o parlamento. Destacam-se, dentre outras questões, as condicionalidades impostas ao financiamento e ao conceito de saúde adotado, entendida como gasto e não como investimento público, que revelam quão frágeis são os consensos sobre a saúde ser um dever do Estado e um direito do cidadão, visando a qualidade geral de vida e uma nação mais saudável.

Todo o processo inicial de descentralização e financiamento do SUS foi regulamentado pelas Normas Operacionais Básicas (NOB), que funcionaram como manuais operacionais do sistema (Martins, 2004). A NOB 01/91 dispôs sobre o financiamento e os requisitos legais para as transferências automáticas. Já a NOB 01/93 estabeleceu "normas e procedimentos reguladores do processo de descentralização da gestão das ações e serviços de saúde". Com a NOB 01/96 foram apresentadas as competências dos níveis municipal, estadual e federal, com a definição do Teto Financeiro Global do Município (TFGM), a importância das comissões intergestores e a necessidade da realização de uma Programação Pactuada e Integrada (PPI) 
entre os municípios. A emissão da NOB 96 não foi acompanhada pela maior autonomia dos municípios. Ao contrário, tornou-os mais dependentes dos recursos federais na medida em que os recursos financeiros, em sua maioria, são vinculados aos programas de saúde, incentivados pelo Ministério da Saúde, não podendo ser redirecionados para outros fins (Marques e Mendes, 2005).

Em que pesem os vários embates provocados pelos constrangimentos econômicos impostos ao sistema, o SUS demonstrou relativa capacidade de resistência às conjunturas mais problemáticas. Visando a superação de problemas identificados, foi publicada a Norma Operacional de Assistência à Saúde (Noas 01/2001), que estabeleceu o processo de regionalização como estratégia de hierarquização dos serviços de saúde e de busca de maior equidade. Propôs-se a elaboração de um Plano Diretor de Regionalização (PDR) e um Plano Diretor de Investimentos (PDI), assim como se introduziram alguns conceitos-chave para a formulação do PDR. Deste modo, a regionalização e a hierarquização dos serviços de saúde buscam impedir a sobreposição de serviços, almejando a articulação dos três níveis de complexidade do sistema - atenção básica, média complexidade e alta complexidade (Carvalho, Martin e Cordoni Júnior, 2001).

Ou seja, a atenção básica (denominação brasileira, adotada pelo Ministério da Saúde) ou atenção primária à saúde (denominação internacional) é o primeiro nível de contato dos indivíduos, da família e da comunidade com o sistema nacional de saúde, constituindo o primeiro elemento de um processo de atenção continuada à saúde. Dentre os atributos requeridos de uma atenção primária de qualidade estão a integralidade e a continuidade dos cuidados, ambos fortemente dependentes de um efetivo sistema de referência e contrarreferência - entendido como mecanismo de encaminhamento mútuo de pacientes entre os diferentes níveis de complexidade dos serviços (Serra e Rodrigues, 2010). A atenção de média/alta complexidade compreende um conjunto de ações e serviços ambulatoriais e hospitalares que objetivam resolver os principais problemas de saúde da população, cuja prática clínica exige a disponibilidade de profissionais especializados e a utilização de recursos tecnológicos de apoio diagnóstico e terapêutico, que não justifique sua oferta em todos os municípios do país (Brasil, 2001).

No ano de 2006, o Ministério da Saúde divulgou o Pacto pela Saúde, tendo como um dos seus componentes o Pacto de Gestão, o qual reafirma a regionalização como uma diretriz do SUS para melhorar o acesso da população aos serviços de saúde. Além disso, a portaria ressalta a relevância de se respeitarem os conceitos de economia de escala e de qualidade da atenção, de forma a desenvolver sistemas eficientes e efetivos (Brasil, 2006).

O discurso oficial, de fato, não é mera retórica. Porém, apesar de toda a evolução na regulamentação do SUS, ainda permanecem modelos inadequados de oferta, cobertura e gasto público em ações e serviços de saúde. O debate continua aberto, pois são ações e serviços de natureza, complexidade e custos diversos, contribuindo para a complexidade da análise os diferentes contextos regionais que os atuais incentivos financeiros federais não superaram (Dain, 2007).

Por outro lado, acesso/acessibilidade a ações e serviços de saúde envolve uma conceituação complexa, que muda ao longo do tempo e de acordo com o contexto. Apresenta-se 
como uma característica da relação multidimensional entre necessidade/demanda/oferta de ações e serviços de saúde, muito relevante para a interpretação do padrão de utilização efetiva de recursos assistenciais, bem como para pesquisas sobre equidade em sistemas de saúde (Travassos e Martins, 2004; Donabedian, 2003). Equidade em saúde supõe que toda pessoa deve ter uma oportunidade justa para alcançar seu potencial pleno de saúde e, mais pragmaticamente, que ninguém deve ser desfavorecido em alcançar seu potencial se isto puder ser evitado, traduzindo-se em valores explícitos de justiça social e sanitária (Braveman e Gruskin, 2003).

Donabedian (2003) optou pelo termo "acessibilidade" e relatou duas dimensões: a sócio-organizacional e a geográfica, apontando que ambas se inter-relacionam. A primeira inclui todas as características da oferta institucionalizada de serviços, com exceção dos aspectos geográficos que obstruem ou aumentam a capacidade das pessoas de alcançarem os mesmos. A acessibilidade geográfica pode ser mensurada pela distância linear, tempo de locomoção, despesa da viagem, entre outros.

Tal é a relevância desta questão que ela foi abordada nos suplementos da Pesquisa Nacional por Amostra de Domićlios (Pnad/IBGE), nos anos de 1998, 2003 e 2008, permitindo um monitoramento das políticas voltadas ao acesso e utilização equitativa de serviços de saúde (Ferreira et al., 2010; Oliveira et al., 2009; Travassos et al. 2008).

A problematização anteriormente descrita foi incorporada na agenda de gestores no nível local, regional e nacional do SUS. Apresenta-se também como tema de debates em canais de manifestação da sociedade brasileira que conformam o controle social do SUS, particularmente em Conferências e Conselhos de Saúde, tornando-se objeto de estudo com especial relevância para grandes aglomerados urbanos; é o caso, por exemplo, dos 26 municípios da Região Metropolitana de Curitiba (RMC) (Pires et al. 2010; Cerqueira e Pupo, 2008).

Considerando o exposto e a importância protagônica do secretário municipal de saúde, compreendido como ator com papel decisivo na gestão do SUS, o objetivo deste estudo foi investigar a prática discursiva dos gestores de secretarias municipais de saúde da RMC, em relação à articulação de níveis de atenção e ao acesso da população de seu município aos serviços de saúde, desde a APS até a média/alta complexidade, e como ele se relaciona com os demais agentes públicos no seu contexto de gestão.

\section{Método}

Realizou-se estudo exploratório com abordagem qualitativa, com entrevistas envolvendo os secretários municipais de saúde dos 26 municípios da RMC (figura 1). Do conjunto convidado a participar deste estudo, no período de dezembro de 2009 a julho de 2010, 16 gestores municipais e um gestor regional participaram da pesquisa, cinco não aceitaram participar e houve dificuldade de agenda com os outros cinco, ou seja, embora aceitando participar, mostraramse indisponíveis na sequência. 

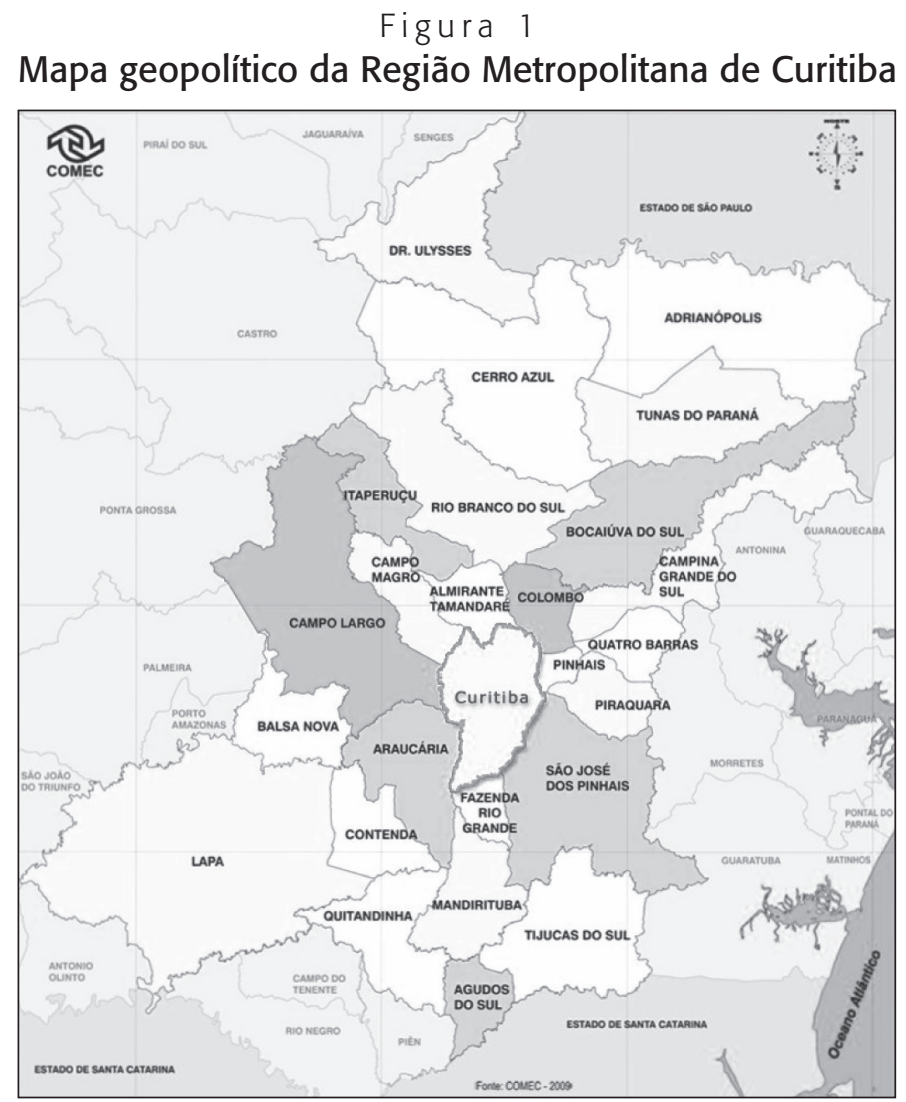

Fonte: Coordenação da Região Metropolitana de Curitiba (Comec), 2012.

Foi utilizada a entrevista não estruturada para que o entrevistado tivesse a possibilidade de discorrer sobre o tema proposto, sem opções de respostas prefixadas (fechadas) pelo pesquisador (Minayo, 2006). As entrevistas foram conduzidas pela própria pesquisadora, após a realização de um teste piloto com um gestor cuja entrevista não foi incluída no estudo. Os gestores foram contatados e esclarecidos previamente quanto aos objetivos da pesquisa. Muitos aceitaram imediatamente, mas para alguns predominou a dificuldade do agendamento das entrevistas.

O roteiro da entrevista contemplou os seguintes eixos: 1) avanços e dificuldades na atenção primária, 2) principais dificuldades encontradas em relação às consultas e aos exames especializados e medidas para melhorar o acesso neste nível, 3) acesso ao atendimento hospitalar, 4) encaminhamentos para a atenção à saúde bucal especializada, 5) participação no Colegiado de Gestão Regional e capacidade de articulação política. Todas as perguntas foram respondidas pelos sujeitos efetivamente entrevistados, que compuseram a amostra final. As entrevistas foram gravadas e depois transcritas, visando primeiramente a leitura das falas na sua forma literal. 
Processou-se, então, à interpretação do material por meio da análise de discurso, buscando o entendimento de práticas discursivas que articulam linguagem, entremeada pelo contexto ideológico e autopercepção do protagonista-gestor, com a inevitável contribuição da conjuntura local do município. A análise do discurso possibilitou compreender a materialidade de enunciados no interior de uma determinada linguagem e a formação de práticas discursivas, já percebida como ação no mundo, além de reconhecer qual é o seu sentido, ou seja, o seu valor e sua dependência com um determinado contexto. Assim, o pressuposto metodológico não é de que somente o texto desvela o contexto, mas também o contrário, o contexto aclara o texto (Rocha e Deusdará, 2005). A interpretação do material permitiu a classificação das práticas discursivas, que foram agrupadas em categorias, respeitando as motivações, as contradições, as similaridades e as convergências, mas também as dessemelhanças nas realidades dos gestores.

Este estudo foi aprovado pelo Comitê de Ética em Pesquisa em Seres Humanos da PUCPR, no 0003278/09, em 16 de setembro de 2009.

\section{Resultados e discussão}

O agrupamento das práticas discursivas, decorrente do roteiro de questões, resultou em cinco categorias conforme detalhado no quadro 1: atenção primária municipal, acesso na média complexidade, atendimento hospitalar, saúde bucal e articulação política. A perspectiva discursiva problematizaria a necessária distância entre os saberes do pesquisador e os produzidos pela coleta de informação junto aos entrevistados.

$$
\text { Quadro } 1
$$

Roteiro de entrevista, categorias de análise e problematização derivadas das entrevistas com gestores municipais da RMC (2011)

\begin{tabular}{|c|c|c|}
\hline Roteiro de entrevista & $\begin{array}{l}\text { Categoria de } \\
\text { análise }\end{array}$ & Problematização \\
\hline $\begin{array}{l}\text { Você poderia descrever o atendimento na } \\
\text { atenção básica do seu município, relatando } \\
\text { os avanços e as dificuldades encontradas? }\end{array}$ & $\begin{array}{l}\text { Atenção primária } \\
\text { municipal. }\end{array}$ & $\begin{array}{l}\text { Contextualizar a atenção primária no município, analisando } \\
\text { a prática discursiva do gestor local e como seus enunciados } \\
\text { constroem/reconstroem sua ação pública na questão da or- } \\
\text { ganização de ações e serviços e no acesso da população. }\end{array}$ \\
\hline $\begin{array}{l}\text { Quais serviços especializados são ofertados } \\
\text { no município? Há dificuldades da adminis- } \\
\text { tração municipal em relação às consultas e } \\
\text { aos exames especializados? Quais as me- } \\
\text { didas necessárias para melhorar o acesso } \\
\text { da população aos serviços especializados } \\
\text { no seu município? }\end{array}$ & $\begin{array}{l}\text { Acesso na média } \\
\text { complexidade }\end{array}$ & $\begin{array}{l}\text { Investigar quais serviços de média complexidade compõem } \\
\text { o repertório de oferta do município, bem como os obstá- } \\
\text { culos de encaminhamento nas relações intermunicipais, } \\
\text { especialmente para serviços que apresentavam dificulda- } \\
\text { de de oferta em toda a RMC. Averiguar alternativas para } \\
\text { melhorar os serviços públicos de saúde e evidenciar se os } \\
\text { gestores conhecem as causas e buscam soluções para as } \\
\text { filas de espera na atenção especializada. }\end{array}$ \\
\hline
\end{tabular}

Continua 


\begin{tabular}{|lll|}
\hline \multicolumn{1}{|c|}{ Roteiro de entrevista } & \multicolumn{1}{c|}{$\begin{array}{c}\text { Categoria de } \\
\text { análise }\end{array}$} \\
\hline $\begin{array}{l}\text { O município tem hospital? Como são enca- } \\
\text { minhados os pacientes? }\end{array}$ & $\begin{array}{l}\text { Atendimento hos- } \\
\text { pitalar. }\end{array}$ & $\begin{array}{l}\text { Constatar como se dá o acesso ao atendimento hospitalar } \\
\text { no município e/ou articulações metropolitanas tais como } \\
\text { uso de central de leitos. }\end{array}$ \\
$\begin{array}{l}\text { Em relação à saúde bucal, como são enca- } \\
\text { minhados os usuários que necessitam de } \\
\text { atenção especializada? }\end{array}$ & Saúde bucal. & $\begin{array}{l}\text { Evidenciar se existe a oferta destes serviços no município e, } \\
\text { caso existam, como se desenvolvem na atenção primária e } \\
\text { em sua articulação com a atenção especializada. }\end{array}$ \\
$\begin{array}{l}\text { Você participa do Colegiado de Gestão } \\
\begin{array}{l}\text { Regional? Como se dá sua participação no } \\
\text { Colegiado de Gestão Regional? }\end{array}\end{array}$ & Articulação política. & $\begin{array}{l}\text { Identificar se os gestores municipais entrevistados operam } \\
\text { em bases colegiadas, e articulam apoios intergovernamen- } \\
\text { tais para buscar melhorias para o seu município. }\end{array}$ \\
\hline
\end{tabular}

Fonte: Dados da pesquisa.

\section{Contextualização da Atenção Primária}

As falas dos sujeitos pontuaram que a APS não é praticada plenamente, em todos os contextos municipais analisados, mas que os mesmos têm se esforçado para organizá-la. Pode-se deduzir que este nível de atenção apresenta-se em diferentes estágios: enquanto o gestor G7 preocupa-se com o processo de trabalhos nos serviços, o gestor G1 ainda está estruturando as Unidades Básicas de Saúde desvinculando-as da assistência hospitalar.

(...) a atenção primária não é praticada plenamente. Ela é praticada apenas como atenção básica e se compromete muito mais com agendamento de atenção especializada do que com a resolução de problemas (G7).

(...) a atenção básica nunca foi tida como prioridade no município. (...) deveria coordenar o sistema. (...) tudo era feito no Hospital. Só a triagem era feita na Unidade, ou seja, era uma extensão do Hospital (G1).

Assim, muitos serviços são fragmentados, atuam de maneira isolada, sendo incapazes de prestar um cuidado contínuo e integral à população. Mendes (2010) afirma que, nestes contextos, a atenção primária não consegue exercer seu papel de coordenadora das redes de atenção e das linhas do cuidado que as pessoas necessitam. Curiosamente, na contramão desta constatação, os gestores cedem ao roteiro do discurso oficial vigente, sobretudo advindo do governo federal, elegendo a Estratégia Saúde da Família (ESF, anteriormente conhecida pela sigla PSF) como apanágio da boa APS e sugerindo que a forma de paliar os problemas já 
estivesse em curso, reorganizando os serviços de saúde municipais conforme os preceitos da Política Nacional de Atenção Básica (Brasil, 2007).

(...) E os avanços a gente consegue com a Equipe de PSF. (...) Então o PSF é o grande pulo da saúde (G10).

O discurso não é confirmado pelas evidências locais, já que o estudo encontrou distintos estágios de organização da rede de APS e evidenciou uma grande expectativa dos gestores na ESF como uma possibilidade futura para estruturar o sistema local de saúde. Tal situação também foi encontrada nos municípios da Região Metropolitana da Baixada Santista, onde os gestores de saúde têm a esperança de reorganizar a APS pela implantação e expansão da ESF (Barboza et al., 2008).

Sabe-se que a ESF não é uma panaceia capaz de resolver, de um só golpe, todos os problemas da APS e, mesmo que carregasse toda esta potencialidade, esta reorganização da atenção com foco na ESF esbarra em muitos problemas para a gestão cotidiana. Destaca-se hoje no Brasil a dificuldade de contratação de médicos para trabalhar no setor público, particularmente em municípios pequenos ou em regiões mais pobres, acarretando uma rotatividade grande destes profissionais e a dificuldade em consolidar o vínculo com a comunidade.

(...) a maior dificuldade que hoje eu tenho é a rotatividade de profissional médico. (...) isso é uma dificuldade muito grande e o que nos causa grande problema na resolutividade e dos problemas, principalmente dos pacientes crônicos, na manutenção dos programas dos pacientes crônicos. Eu acabo atendendo somente pacientes agudos (G3).

A rotatividade dos profissionais constituiu-se em um importante obstáculo ao desenvolvimento do trabalho, dentre vários, destacando-se também: i) a precarização de vínculos trabalhistas para a equipe de saúde; ii) os modelos de prática e as ideologias ocupacionais reforçadas durante a formação com foco no modelo biomédico - tecnicista, mecanicista, fragmentário e privatista — , reduzindo o processo saúde-doença à sua dimensão anatomofisiológica, excluindo as dimensões histórico-sociais envolvidas no processo saúde/doença, e localizando suas principais estratégias de intervenção nas partes doentes do corpo, mediante trabalho regulado pelo mercado; iii) estilos de gestão autoritários, a ausência de vínculo com a comunidade e más condições de trabalho que caracterizam muitos serviços públicos. Esta dificuldade, também encontrada em outros estudos (Medeiros et al., 2010; Mendonça et al., 2010), é relatada pela maioria dos gestores, principalmente nos municípios mais distantes da capital.

O financiamento insuficiente para as ações de saúde está presente nos discursos da maioria dos sujeitos.

(...) nós não podemos suportar um programa desse (Saúde da Família), onde nós recebemos do governo, seis mil do governo federal e mil do governo estadual, sete mil. E gastamos entre 30, 
40, 45 mil por equipe, certo? Nós não podemos suportar isso, esse ônus em cima da nossa cabeça (G10).

A dificuldade relatada é agravada pela distância entre os municípios e a capital (Serra e Rodrigues, 2010), forçando os municípios a tentar mecanismos contraditórios de compensação salarial, propondo-se a pagar remunerações cada vez mais altas para fixar os profissionais, principalmente médicos, em municípios que operam com baixos orçamentos. O financiamento das ações ocorre em descompasso com as responsabilidades estabelecidas pela universalização e descentralização do sistema. Apesar da tendência mais equitativa das transferências federais do SUS, a alocação destes recursos não superou as desigualdades inter e intrarregionais das receitas públicas municipais, nem a condição desfavorável dos pequenos e médios municípios (Dain, 2007).

Alguns gestores investiram na estrutura adquirindo equipamentos, carros e ampliando a cesta de medicamentos como forma de melhorar a atenção primária no seu município. Em relação aos processos de trabalho, apenas dois sujeitos mencionaram intervir no modus operandi das equipes por meio de sensibilização e capacitações para estabelecer uma atenção à saúde resolutiva e qualificada. A organização dos processos de trabalho é uma questão que precisa ser enfrentada para a mudança dos serviços, no sentido de se instituírem práticas e saberes necessários para o cuidado integral à saúde (Feuerwerker, 2005; Franco e Magalhães Júnior, 2003).

\section{Acesso na média complexidade}

Poucos gestores relataram que os serviços de média complexidade não são um problema para o sistema municipal. A maioria dos entrevistados admite dificuldades no acesso a consultas e exames especializados, o que gera uma interrupção nas linhas de cuidado, revelando a fragmentação ou inexistência de rede de saúde (Mendes, 2010).

(...) hoje, no município, nós temos uma licitação onde eu compro consultas e exames especializados com recursos próprios do município pra tentar minimizar este problema, mas ainda é problema, pois eu tenho uma demanda reprimida muito grande em certas especialidades é... principalmente o acesso a cirurgias em hospitais na questão da ortopedia, na neuro, na endócrino que são "nós" que temos dentro do nosso sistema (G3).

(...) Só que é o seguinte: a linha de atendimento, ela vai até um certo momento, e depois ela é interrompida (G10).

Esta categoria evidenciou também uma preocupação dos sujeitos quanto à pressão que a população exerce na busca de serviços de saúde centrados no médico, particularmente, o especialista. 
(...) percebemos que as equipes ficam bastante, assim, limitadas a atender aquela demanda (...), de fazer o atendimento médico. E a própria população exige isso, a população não entende, por exemplo, que uma sala de... às vezes tem algumas localidades que nós temos só a sala de enfermagem, né?! para o atendimento, pra medicação, pras palestras, pro trabalho de, de... orientação, e que a população não quer isso, a população quer o atendimento do médico (...) (G11).

No modelo assistencial vigente, medicocêntrico, o fluxo das unidades de APS é voltado para as consultas médicas (Serra e Rodrigues, 2010). A reorganização dos processos de trabalho é fundamental, no sentido de colocar o profissional de saúde, mais especificamente o médico, operando em equipe multiprofissional de saúde e centrado no usuário e suas necessidades (Franco e Magalhães Júnior, 2003). Dessa forma, o acolhimento é indispensável para que as necessidades de saúde trazidas pelos usuários e o que a equipe de saúde tem a oferecer possam imprimir mudanças no modelo assistencial, promovendo saúde e prevenindo doenças, além de desafogar a pressão por consultas médicas (Gomes e Pinheiro, 2005).

Cunha e Vieira-da-Silva (2010) analisaram a organização do sistema e os serviços de saúde de um município da Bahia. O estudo revelou que, em face da ausência de protocolos para o agendamento, acolhimento e cuidado dentro da rede básica, a acessibilidade sofre grande influência das características organizacionais das unidades, que traduzem os diferentes perfis profissionais e de gestão local.

A distância entre os municípios e a capital foi apontada como barreira para o acesso, pois o município tem de disponibilizar transporte devido às baixas condições socioeconômicas da população.

(...) pra fazer uma consulta o município tem que disponibilizar um veículo, porque a nossa população não tem nem condições de ir por conta própria. E se ela for por conta própria do nosso município pra outro pra fazer uma consulta especializada, ela gasta dois dias. Ou seja, no mesmo dia ela não consegue ir e voltar e estar lá no horário da consulta (G6).

Os discursos enfatizaram forte dependência com o município polo e apontaram a central de marcação de consultas de Curitiba como ineficiente para atender as demandas da região metropolitana.

(...) Você vai pra Central de Atendimento. Aonde é a Central de Atendimento? Curitiba. Curitiba, claro, a demanda deles também é muito grande, não tenho dúvida nenhuma, tudo cai em Curitiba, tudo cai em Curitiba, né! Que o sistema é arcaico, deve ser um sistema arcaico, porque você liga pra lá, você não consegue, é... acessar nada, acessar nada. Então, o que... que eles tão fazendo hoje? Nós temos a marcação de consultas, né?! Hoje temos a marcação de consulta, ela funciona por cinco minutos, tem uma hora lá das sete e meia que ela funciona cinco, sete minutos e cai o sistema (G10). 
Igualmente, na Região Metropolitana da Baixada Santista as diferenças intrarregionais no acesso aos serviços de saúde especializados foram identificadas. Na média complexidade, observou-se forte dependência do município-sede da microrregião. A alta complexidade apresentou importante estrangulamento na área de tráumato-ortopedia cirúrgica (Barboza et al., 2008).

Cerqueira e Pupo (2008) estudaram o acesso aos serviços de saúde em comunidades com precárias condições de vida. A maior barreira identificada foi a baixa capacidade do sistema em responder adequadamente e com agilidade às demandas e necessidades de saúde, podendo ser exemplificada como oferta insuficiente de serviços de atenção especializada, longa espera por exames, indisponibilidade de determinados medicamentos e morosidade na obtenção do cuidado.

Os gestores entrevistados citaram a necessidade de realizar a regulação dentro do município, melhorar a qualidade da APS e receber maior financiamento para estes serviços.

(...) A média complexidade também, ela tem uma, uma... uma realidade distorcida em função de muita coisa que poderia estar sendo atendida na atenção básica acaba não sendo atendida né, e principalmente, eu vejo também a dificuldade na regulação disso, né, em definição de linhas guias ou protocolos, pra a gente ter um dimensionamento real do que significa em termos da necessidade de oferta, né (G8).

Autores têm defendido que a institucionalização de ações mais articuladas, com rotinas definidas para o atendimento e encaminhamento dos usuários na rede, pode impactar positivamente os resultados da acessibilidade (Cunha e Vieira-da-Silva, 2010). Este pressuposto também foi encontrado no discurso de gestores.

(...) nós temos intenção de fazer com que a demanda se organize a partir da sua necessidade e não a partir da oferta. (...) em vez de mandar os pacientes adiante para os especialistas, a gente poderia fazer um esforço de trazer o especialista à equipe de saúde da família e resolver junto, de modo a fazer uma transmissão de técnicas e conhecimentos e reduzir a demanda que é até inflacionada pelas equipes de saúde quando chegam numa população muito carenciada e que é colonizada pela ideia de fazer aquele exame, muitas vezes de uma forma até obsessiva (G7).

Os gestores compreendem que uma APS resolutiva e organizada reduz a demanda por consultas e exames especializados, reservando os recursos públicos para garantir os procedimentos realmente necessários (Starfield, 2004; Franco e Magalhães Júnior, 2003).

(...) o que precisa é lá na atenção básica, na unidade de saúde, o paciente ser melhor avaliado, né, melhor examinado, né... na história do paciente, na anamnese mesmo. Então o que eu vejo que falta é realmente um atendimento de melhor qualidade na atenção básica, né, na unidade de saúde (G9). 
Organizar os serviços de referência e contrarreferência, os fluxos e as centrais de regulação é necessário para equalizar a oferta de serviços intermunicipais em uma região de saúde. Simultaneamente, a incorporação de tecnologias do cuidado na APS, na forma de estrutura sanitária ou de conhecimentos aplicados, amplia a resolutividade das unidades de saúde (Ferreira et al., 2010; Pires et al., 2010).

A formação de um Consórcio Metropolitano de Saúde também foi apontada como alternativa para amenizar a demanda reprimida na média complexidade: “(...) o consórcio no meu município será de grande valia" (G5).

Tal necessidade foi amplamente discutida pelos gestores da região metropolitana e o aporte de recursos para viabilizar sua implantação foi reivindicado junto ao governo do estado. A Secretaria de Estado da Saúde parece convergir para esta posição, firmando convênio para repasse de recursos de implantação e custeio do Consórcio Metropolitano de Saúde do Paraná (Comesp), em julho de 2010.

\section{Atendimento hospitalar}

Dificuldades várias, e algumas soluções, também foram apontadas pelos gestores nesta categoria. Contratos de serviços com hospital privado de um município limítrofe à capital (Campo Largo), difícil acesso por meio da Central de Leitos de Curitiba e hospitais próprios com baixa complexidade/resolutividade foram relatados.

(...) quando eu necessito de um atendimento de média e alta, eu preciso acessar a Central de Leitos; que é um estresse, que você também fica com uma dificuldade muito grande de conseguir essa vaga, esse leito, né, através da Central e por conta disso o município então tomou uma decisão política própria de manter um contrato com o Hospital de Campo Largo para também dar vazão a estes atendimentos de média complexidade e alta complexidade, principalmente com acesso a UTI geral e UTI neonatal (G3).

(...) O que fica fora da resolutividade do Hospital, ele é encaminhado via Central de Leitos de Curitiba que tem... nos atende assim... uns 60 a $70 \%$ se tem facilidade e tem uns 30\% 40\% desses pedidos que são muito difícil de conseguir, principalmente no paciente mais grave e aquele que precisa efetivamente de uma UTI (G15).

(...) pro sistema integral, Curitiba e região metropolitana, realmente ainda existe uma defasagem de leitos que precisa ser equacionada. Acho que isso é uma grande responsabilidade e um papel importante da Secretaria de Estado da Saúde em organizar toda essa atenção, pra que a gente possa ter o paciente atendido é... no, na sua necessidade, né, no tempo certo, né, local certo com o custo certo (G16). 
Os discursos aludem à importância da conformação de redes de atenção à saúde, que são organizações poliárquicas de conjuntos de serviços de saúde ligados entre si por um objetivo comum (Mendes, 2010). Esta organização possibilita uma atenção à saúde contínua e integral, coordenada pela APS — prestada no tempo certo, no lugar certo, com o custo certo, com a qualidade certa e de forma humanizada - , e com responsabilidades sanitárias e econômicas por esta população.

Para três gestores municipais, incluindo o município polo, os encaminhamentos hospitalares não constituem um problema, pelo fato de apresentarem estrutura hospitalar relativamente adequada, tanto do ponto de vista da oferta quanto da resolutividade.

\section{Saúde bucal}

Na saúde bucal, o acesso aos serviços e a continuidade do cuidado são desafios enfrentados pelos gestores. Atender a demanda por saúde bucal que emerge na APS e exige linhas de cuidado, incluindo outros níveis de atenção, é um problema para a maioria dos municípios.

(...) temos poucos profissionais, não temos a estrutura necessária. (...) mesmo na atenção de primeiras consultas odontológicas nós não temos atingido. Temos três profissionais de vinte horas de odontologia que realmente não é suficiente para, para a nossa comunidade (G1).

Observou-se, no estudo de Leal e Tomita (2006), que os gestores têm a percepção do acesso escasso e desigual para esta questão. Também se identificou que a atenção à saúde bucal ocorre de forma pouco organizada, com acesso restrito ainda centrado nas intervenções remanescentes de antigos programas de saúde do escolar. A baixa efetividade deste sistema é observada nas filas de espera.

A atenção de saúde bucal especializada é oferecida por poucos municípios.

(...) nós tentamos encaminhar às vezes para um sistema privado e daí a pessoa, às vezes, acaba pagando para receber esse atendimento de média complexidade em odontologia (G1).

(...) a gente tem um serviço credenciado, nós pagamos pra dar conta disso (G9).

Registra-se a necessidade de os gestores estruturarem e organizarem a saúde bucal, fundamentada no planejamento de ações, para ampliar o acesso e garantir a continuidade do tratamento, incluindo um melhor conhecimento e gestão das disponibilidades oferecidas pelo governo federal, com a Política Nacional de Saúde Bucal — Brasil Sorridente, a qual apoia a implantação de equipes de saúde bucal na ESF, além Centros de Especialidades Odontológicas, Laboratórios Regionais de Prótese Dentária e atenção hospitalar e/ou oncológica. 


\section{Articulação política}

Observou-se uma confiança, ao menos no plano retórico, de muitos secretários na atuação do Colegiado de Gestão Regional, que é o Conselho Regional dos Secretários Municipais de Saúde (Cresems).

(...) Mas é a primeira vez que eu vi uma união, o que eu tô falando é a respeito dos secretários, se reunir, trocar ideia, você fazer um... fazer uma frente junto ao governo, conversar, botar o governo pra sentar pra nos escutar, coisa que nunca fizeram, você entendeu? (G10).

Apenas um secretário relatou descontentamento e ceticismo com a atuação do Colegiado de Gestão Regional, apesar de reconhecer uma melhora na mobilização dos seus pares.

(...) Eu participo disso há..., tá indo agora aí pra quase 10 anos. O Cresems melhorou a questão de mobilização, mas eu não vejo... eu não vejo o Cresems hoje atuando pra os municípios, né? (...) e hoje você vê, ahn... o Cresems muito, é... muito perto do Estado, ahn... preocupado em ajudar o Estado a resolver as suas demandas e não as nossas (G4).

O discurso do G4 permite inferir sobre a diversidade de olhares e falas na construção de uma determinada ordem, assim como sobre as contradições que permeiam o funcionamento de colegiados gestores, sobretudo quando há distintas agremiações políticas ali representadas por seus membros. Neste caso, seria preciso compreender em que perspectivas a relação social de poder político se constrói no plano discursivo. A gestão colegiada de uma área como a saúde cria não somente uma possibilidade democrática de condução dos interesses públicos, mas também uma arena de conflitos e disputas entre atores políticos defendendo sua agenda programática específica, tanto no sentido das questões de saúde pública quanto no sentido eleitoral — já que com o setor saúde também se ganham ou se perdem eleições estaduais e municipais.

Diante do desafio de superar o risco da fragmentação das políticas e programas de saúde, o Ministério da Saúde instituiu o Pacto de Gestão, estabelecendo diretrizes para a regionalização das ações e serviços de saúde. Este instrumento de gestão orienta que os gestores de saúde de uma região devem constituir um espaço permanente de pactuação e cogestão solidária e cooperativa por meio do Colegiado de Gestão Regional (Brasil, 2006).

Hartz e Contandriopoulos (2004) discorrem sobre a importância da integração de serviços de saúde por meio de redes assistenciais, reconhecendo a interdependência dos atores e organizações, em face da constatação de que nenhuma delas dispõe da totalidade dos recursos e competências necessários para a solução dos problemas de saúde de uma população em seus diversos ciclos de vida. Os autores citam que é necessário desenvolver mecanismos de cooperação e coordenação próprios de uma gestão eficiente e responsável dos recursos coletivos, a qual responda às necessidades de saúde individuais em âmbitos local e regional. 


\section{Conclusão}

Com base nos discursos dos gestores, a análise mostrou que os municípios se encontram em diferentes estágios de estruturação da APS. Foram identificadas acentuadas diferenças em termos de disponibilidade e uso de recursos materiais e financeiros, além da força de trabalho em saúde, trazendo implicações sobre a governabilidade do projeto de governo da respectiva secretaria, bem como sobre o poder nas relações de gestão da RMC.

A ESF foi citada pela maioria como forma de reorganização da APS e oferta de serviços mais resolutivos. Outra preocupação dos secretários municipais é a pressão exercida pela demanda por consultas médicas e a desvalorização das ações desenvolvidas pelo restante da equipe multiprofissional de saúde, fato que em certa medida também fragiliza o processo de implantação, não apenas da ESF, mas dos conceitos e atributos internacionais que definem a APS de qualidade, incluindo a educação, a promoção da saúde e a prevenção de doenças, por meio de agentes que atuam em várias esferas, algumas inclusive extrapolando o setor saúde e alcançando o plano intersetorial.

O difícil acesso ao sistema de marcação de consultas e exames especializados e a distância entre os municípios e a capital foram apontados como agravantes para o acesso a serviços de média/alta complexidade. Na questão do atendimento hospitalar, uma parcela dos gestores aponta o difícil acesso via Central de Leitos de Curitiba, especialmente o encaminhamento de pacientes para leitos de UTI geral ou UTI neonatal. Quanto à saúde bucal, observou-se que os municípios ainda não conseguem responder às demandas na APS, muito menos na média complexidade.

Finalmente, os gestores apontam como necessária a regionalização dos serviços de média/alta complexidade e, em alguns casos, até mesmo a microrregionalização, uma vez que se trata de uma área de abrangência tão grande quanto as diferenças entre as realidades de alguns municípios aqui estudados. Neste último aspecto, é indispensável ressaltar não apenas as distâncias rodoviárias e obstáculos naturais entre os municípios, mas também as discrepâncias econômicas, de desenvolvimento social e diferenças culturais que permeiam um espaço geográfico comum.

\section{Referências}

BARBOZA, Renato et al. Acesso e estruturação da Atenção Básica na Região Metropolitana da Baixada Santista. In: ESCUDER, Maria M. L.; MONTEIRO, Paulo H. N.; PUPO, Ligia R. (Org.). Acesso aos serviços de saúde em municípios da Baixada Santista. São Paulo: Instituto de Saúde, 2008. p. 29-50.

BRASIL. Ministério da Saúde. Atenção Especializada em Saúde no Brasil: indicadores e tabelas selecionados. Brasília: Ministério da Saúde, 2004. 
BRASIL. Ministério da Saúde. Diretrizes operacionais dos Pactos pela Vida, em Defesa do SUS e de Gestão. Brasília: Ministério da Saúde, 2006.

BRASIL. Ministério da Saúde. Política nacional de atenção básica. Brasília: Ministério da Saúde, 2007.

BRASIL. Ministério da Saúde. Portaria no 95 do Ministério da Saúde, de 26 de janeiro de 2001. Regionalização da assistência à saúde: aprofundando a descentralização com equidade no acesso. Norma operacional da assistência à saúde Noas-SUS 01/01. Diário Oficial da União, Brasília, 26 jan. 2001.

BRAVEMAN, Paula; GRUSKIN, Sofia. Defining equity in health. Journal of epidemiology and community health, v. 57, n. 4, p. 254-258, 2003.

CAMPOS, Gastão W. D. S. Reforma política e sanitária: a sustentabilidade do SUS em questão? Ciência \& Saúde Coletiva, v. 12, p. 301-306, 2007.

CARVALHO, Brígida G.; MARTIN, Gilberto B.; CORDONI JÚNIOR, Luiz. A organização do sistema de saúde no Brasil. In: ANDRADE, Selma Mafei; SOARES, Darli Antonio; CORDONI JÚNIOR, Luiz (Org.). Bases da saúde coletiva. Londrina: Ed. UEL, 2001. p.27-59.

CERQUEIRA, Monique B.; PUPO, Ligia R. Modos de vida e acesso em duas favelas da Baixada Santista. In: ESCUDER, Maria M. L.; MONTEIRO, Paulo H. N.; PUPO, Ligia R. (Org.). Acesso aos serviços de saúde em municípios da Baixada Santista. São Paulo: Instituto de Saúde, 2008. p. 193-214.

COMEC. Coordenação da Região Metropolitana de Curitiba. Divisão política. Disponível em: <www. comec.pr.gov.br/arquivos/File/RMC_2008_politico1.pdf>. Acesso em: 6 jun. 2012.

CONASS. Conselho Nacional de Secretários de Saúde. Assistência de média e alta complexidade no SUS. Brasília: Conass, 2007.

CUNHA, Alcione B. O.; VIEIRA-DA-SILVA, Ligia M. Acessibilidade aos serviços de saúde em um município do estado da Bahia, Brasil, em gestão plena do sistema. Cad. Saúde Pública, v. 26, n. 4, p. 725-737, 2010.

DAIN, Sulamis. Os vários mundos do financiamento da Saúde no Brasil: uma tentativa de integração. Ciênc. Saúde Coletiva, Rio de Janeiro, v. 12, p. 1851-64, 2007.

DONABEDIAN, Avedis. An introduction to quality assurance in health care. Nova York: Oxford University Press, 2003.

FERREIRA, Janise B. B. et al. O complexo regulador da assistência à saúde na perspectiva de seus sujeitos operadores. Interface - Comunic., Saúde, Educ., v. 14, n. 33, p. 345-358, 2010.

FEUERWERKER, Laura. Modelos tecnoassistenciais, gestão e organização do trabalho em saúde: nada é indiferente no processo de luta para a consolidação do SUS. Interface - Comunic., Saúde, Educ., v. 9, n. 18, p. 498-506, 2005.

FRANCO, Túlio B.; MAGALHÃES JÚNIOR, Helvécio M. Integralidade na assistência à saúde: a organização das linhas de cuidado. In: MERHY, Emerson E. et al. O trabalho em saúde: olhando e experienciando o SUS no cotidiano. 2. ed. São Paulo: Hucitec, 2003. p. 125-133. 
GOMES, Márcia C. P. A.; PINHEIRO, Roseni. Acolhimento e vínculo: práticas de integralidade na gestão do cuidado em saúde em grandes centros urbanos. Interface - Comunic., Saúde, Educ., v. 9, n. 17, ago. 2005.

HARTZ, Zulmira M. A.; CONTANDRIOPOULOS, André-Pierre. Integralidade da atenção e integração de serviços de saúde: desafios para avaliar a implantação de um "sistema sem muros". Cad. Saúde Pública, Rio de Janeiro, v. 20, supl. 2, p. S3331-S3336, 2004.

LEAL, Rosana B.; TOMITA, Nilce E. Assistência odontológica e universalização: percepção de gestores municipais. Ciênc. Saúde Coletiva, Rio de Janeiro, v. 11, n. 1, p. 155-160, 2006.

LEVCOVITZ, Eduardo; LIMA, Luciana D.; MACHADO, Cristiani V. Política de saúde nos anos 90: relações intergovernamentais e o papel das Normas Operacionais Básicas. Ciênc. Saúde Coletiva, Rio de Janeiro, v. 6, n. 2, p. 269-291, 2001.

MARQUES, Rosa M.; MENDES, Áquila. Os dilemas do financiamento do SUS no interior da seguridade social. Economia e Sociedade, v. 14, n. 1, p. 159-175, 2005.

MEDEIROS, Cássia R. G. et al. A rotatividade de enfermeiros e médicos: um impasse na implementação da Estratégia de Saúde da Família. Ciênc. Saúde Coletiva, v. 15, supl. 1, p. 1521-1531, 2010.

MENDES, Eugênio V. As Redes de Atenção à Saúde. Ciênc. Saúde Coletiva, v. 15, n. 5, p. 2297-2305, 2010.

MENDONÇA, Maria H. M. et al. Desafios para a gestão do trabalho a partir de experiências exitosas de expansão da Estratégia Saúde da Família. Ciênc. Saúde Coletiva, v. 15, n. 5, p. 2355-2365, 2010.

MINAYO, Maria C. S. O desafio do conhecimento: pesquisa qualitativa em saúde. 9. ed. São Paulo: Hucitec, 2006.

OLIVEIRA, Lúcio H. D. et al. Cidadãos peregrinos: os "usuários" do SUS e os significados de sua demanda a prontos-socorros e hospitais no contexto de um processo de reorientação do modelo assistencial. Ciênc. Saúde Coletiva, Rio de Janeiro, v. 14, n. 5, p. 1929-1938, 2009.

PIRES, Maria R. G. M. et al. Oferta e demanda por média complexidade/SUS: relação com atenção básica. Ciênc. Saúde Coletiva, Rio de Janeiro, v. 15, supl. 1, p. 1009-1019, 2010.

ROCHA, Décio; DEUSDARÁ, Bruno. Análise de conteúdo e análise do discurso: aproximações e afastamentos na (re)construção de uma trajetória. Alea: Estudos Neolatinos, v. 7, p. 305-322, 2005.

SARMENTO, Krishnamurti M. A.; TOMITA, Shiro; KOS, Arthur O. A. O problema da fila de espera para cirurgias otorrinolaringológicas em serviços públicos. Rev. Bras. Otorrinolaringol., v. 71, n. 3, p. 256-262, 2005.

SERRA, Carlos G.; RODRIGUES, Paulo H. A. Avaliação da referência e contrarreferência no Programa Saúde da Família na Região Metropolitana do Rio de Janeiro. Ciênc. Saúde Coletiva, Rio de Janeiro, v. 15, supl. 3, p. 3579-86, 2010.

SOUZA, C. Governos e sociedades locais em contextos de desigualdades e de descentralização. Ciênc. Saúde Coletiva, Rio de Janeiro, v. 7, p. 431-442, 2002. 
STARFIELD, Bárbara. Atenção Primária: equilíbrio entre necessidades de saúde, serviços e tecnologia. Brasília: Unesco Brasil; Ministério da Saúde, 2004.

TRAVASSOS, Cláudia et al. Os Suplementos Saúde na Pesquisa Nacional por Amostra de Domicílios (Pnad) no Brasil. Rev. Bras. Epidemiol., São Paulo, vol. 11, supl. 1, p. 98-112, 2008.

TRAVASSOS, Cláudia; MARTINS, Mônica. Uma revisão sobre os conceitos de acesso e utilização de serviços de saúde. Cad. Saúde Pública, Rio de Janeiro, v. 20, supl. 2, p. S190-S198, 2004.

VIACAVA, Francisco. Acesso e uso de serviços de saúde pelos brasileiros. Radis, n. 96, ago. 2010. Disponível em: <www4.ensp.fiocruz.br/radis/96/pdf/radis_96.pdf>. Acesso em: 4 out. 2010.

Sandra Lúcia Vieira Ulinski Aguilera é doutoranda no Programa de Pós-graduação em Odontologia, área de concentração em Saúde Coletiva, da Pontifícia Universidade Católica do Paraná (PUCPR). E-mail: sandraulinski@hotmail.com.

Beatriz Helena Sottile França é professora do Programa de Pós-graduação em Bioética da Pontifícia Universidade Católica do Paraná (PUCPR). E-mail: beatriz.franca@pucpr.br

Simone Tetú Moysés é professora do Programa de Pós-graduação em Odontologia da Pontifícia Universidade Católica do Paraná (PUCPR). E-mail: simone.moyses@pucpr.br.

Samuel Jorge Moysés é professor do Programa de Pós-graduação em Odontologia da Pontifícia Universidade Católica do Paraná (PUCPR). E-mail: s.moyses@pucpr.br. 
